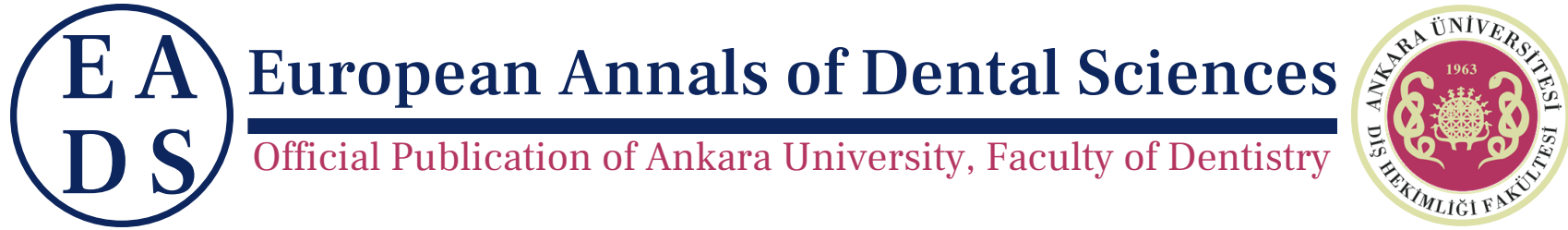

EADS, 2021, 48 (3), 108-112

\title{
Knowledge, Attitude and Practices of Dental Patients About Cross-infection and Infection Control
}

\author{
Meltem Tekbaş-Atay ${ }^{1}{ }^{*}$ and Mediha Büyükgöze-Dindar ${ }^{2}$ \\ ${ }^{1}$ Department of Restorative Dentistry, Faculty of Dentistry, Trakya University, Edirne, Turkey and ${ }^{2}$ Health Science \\ Vocational College, Trakya University, Edirne, Turkey \\ *Corresponding Author; meltemtekbas@hotmail.com
}

\begin{abstract}
Purpose: This study aimed to evaluate the patient's knowledge, attitude, and practice of cross-infection control in dentistry. Materials \& Methods: This cross-sectional study was conducted at the Faculty of Dentistry, Trakya University. In this study, 250 patients (134 female and 116 male) aged 18 years and older (35.5 \pm 13.9$)$ participated and data were collected using a questionnaire containing questions to determine the knowledge, attitudes, and practices related to cross-infection and infection control. Required personal and socio-demographic data were obtained. A chi-square test was conducted for categorical variables. Kruskal Wallis and Mann-Whitney $U$ tests were used to compare questionnaire scores $(\mathrm{p}<0.05)$.

Results: Most of the participants (30.5\%) reported that their sources of information on dental infection control were social media. Knowledge scores of females were statistically significantly higher than males $(\mathrm{p}=0.005)$ and participants living in the city were significantly higher than those living in the town $(\mathrm{p}=0.015)$. Knowledge scores of health-care workers were significantly higher than both other workers and unemployed/students ( $\mathrm{p}=0.001, \mathrm{p}=0.004$, respectively). Regarding participants' attitudes and practices, only $29.2 \%$ of the participants questioned the dentists about the contagious disease, and only $36 \%$ asked about the sterilization method of the dental instruments. Most of the participants perceived that wearing gloves, masks, eyewear, and face shield would protect both patients and dentists.

Conclusion: Participants in this study seem to have a satisfactory level of knowledge about cross-infection and infection control methods in the nowadays' pandemic condition. However, dental health professionals should make additional efforts to educate and encourage dental patients.
\end{abstract}

Key words: cross infection; dental health survey; infection control; questionnaire

\section{Introduction}

Infection is recognized as one of the most critical causes of mortality and morbidity associated with clinical, diagnostic, and therapeutic procedures. ${ }^{1}$ Cross-infection, on the other hand, can be defined as the transmission of microorganisms that may cause infection in a clinical setting between patient, physician, and assistant. Additionally, the term includes various settings where patients obtain health care and dental clinics are also one of the environments where disease transmission may occur easily. ${ }^{2}$ Life-threatening viral or bacterial infections such as Mycobacterium tuberculosis, Human Immunodeficiency Virus (HIV), Hepatitis B and C viruses (HBV and HCV), severe acute respiratory syndrome (SARS-CoV-2), and methicillin-resistant Staphylococcus aureus (MRSA) can easily be transmitted during dental treatment through direct contact with saliva, blood and indirect contact with contaminated equipment, or instruments. ${ }^{3-5}$ Besides, dental care workers can be infected through needle or sharp instrument injuries, inhalation, or inoculation of infected air droplets. ${ }^{6}$

One milliliter of oral secretions contains approximately 100 million microorganisms. ${ }^{7}$ The fact that oral secretions contain more microorganisms than feces is an important indicator that the dentistry environment is dangerous and that patients and staff are also at high risk for infections. Patients who seek dental treatment could be carriers of some infectious diseases or in the prodromal stage. Furthermore, many infectious diseases have latent periods or a post-infection period called as "window period" in which antibodies cannot be identified, and patients may be unaware of their condition. ${ }^{8}$ Therefore, the Centers for Disease Control and Prevention (CDC) recommends that each patient should be considered potentially infectious in dental practice and precautions should be taken. 9

Dental patients' attitudes towards cross infection and infection control have been studied by many researchers. ${ }^{5,10-12}$ However, 
these studies belong to the pre-coronavirus disease (COVID-19) outbreak and it is thought that patient awareness has increased in this process. Consequently, the studies need to be updated. This study aimed to determine the knowledge, attitude and practices of dental patients about cross-infection and infection control.

\section{Materials and Methods}

This study was conducted on patients who were applied to Trakya University Faculty of Dentistry for treatment between March-June 2021 after the necessary approval from Trakya University Scientific Research Ethics Committee (TUTF-BAEK 2021/121) was obtained. A cross-sectional questionnaire containing questions to determine the knowledge, attitudes and, practices related to cross-infection and infection control was administered to volunteers aged 18 years and older. Patients with severe disorders and mental diseases were excluded from this study. A total of 250 patients, 134 female and 116 male, were included in the present study. The questionnaire was designed in light of the previous studies in the literature and distributed to the patients in this study. An informed consent form was signed by the participants before the questionnaire was administered.

The questionnaire required personal and socio-demographic data of the participants (e.g., age, gender and occupation), sources of information about cross-infection and infection control (social media, television, books, newspapers, friends/relatives and other sources), knowledge, attitudes, practices and other opinions on infections that can be transmitted in dental clinics (e.g., HBV, HCV, HIV/AIDS, TB and SARS-CoV-2) and infection control methods to prevent contamination.

Patients' level of knowledge about preventive measures for cross-infection was determined by their response to twelve statements on a three-point Likert scale. In these statements, the participants' knowledge about the importance of wearing gloves, masks, and protective eyeglasses during dental practice was questioned. Additionally, patients were questioned about their perceptions of the significance of replacing gloves after each treatment and after touching the different surfaces outside the treatment area. Patients' attitudes and practices towards the necessary measures for prevention of cross-infection during dental practice were assessed by seven Multiple Choice Questions (MCQs). Participants were also asked for their opinions on preventive measures during dental care maintenance. Each knowledge question was scored; "1" for correct answers and " 0 " for incorrect or unknown answers. Total knowledge score was calculated between 0-12 and the scores were classified in three sections, with $<6$ of correct answers considered poor, $6-8$ as fair, and $>8$ as satisfactory.

Statistical analysis was performed using IBM SPSS Statistics for Windows, Version 23.0 (SPSS Inc., Chicago, IL, USA). Descriptive (frequency distribution and percentages) and inferential statistics were given. A chi-square test was conducted for comparisons of categorical variables. Kruskal Wallis and Mann-Whitney U tests were used to compare questionnaire scores. The significance limit was $\mathrm{p}<0.05$.

\section{Results}

The overall response rate was $86 \%$ and 250 patients ( $53.6 \%$ female and $46.4 \%$ male) with a mean age of $35.5 \pm 13.9$ years were included in the present study. The findings showed that $14 \%$ of the participants were healthcare workers and $36.8 \%$ were students or unemployed. $30.5 \%$ of the participants reported that their sources of information on dental infection control were social media, followed by other sources $(30.3 \%)$, family/friends (21.2\%), television (9.6\%), and books/newspaper (8.4\%). Relationships between the sociodemographic characteristics of the participants and levels of knowledge

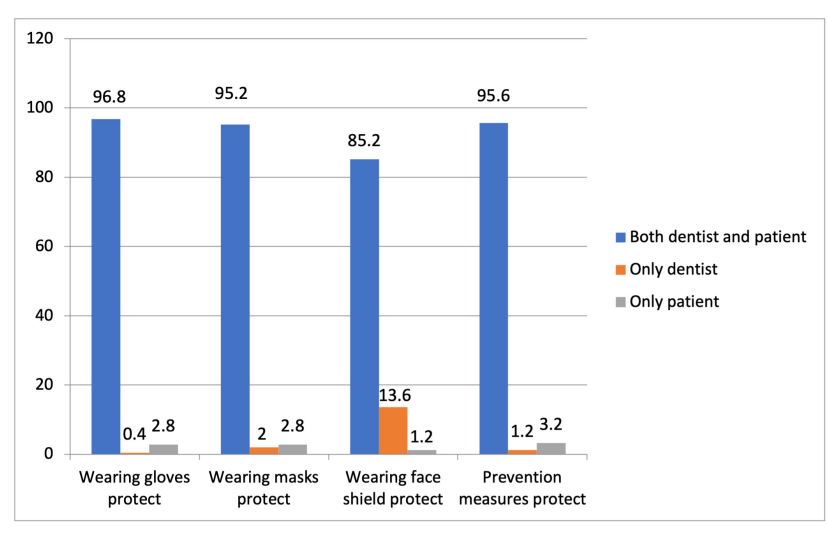

Figure 1. Distribution of the opinions of participants regarding who will be protected by protective measures during dental practice

about dental infection are given in Table 1.

Knowledge scores of females were statistically significantly higher than males ( $\mathrm{p}=0.005)$. Place of residence also affected knowledge scores. The scores of participants living in the city were significantly higher than those living in the town $(\mathrm{p}=0.015)$. In addition, the knowledge scores of healthcare workers were significantly higher than both other workers and unemployed/students $(\mathrm{p}=0.001$, $\mathrm{p}=0.004$, respectively).

Regarding participants' attitudes and practices towards the required measures for prevention of cross-infection during dental care, Table 2 shows that only $29.2 \%$ of the participants questioned the dentists about the contagious disease, and only $36 \%$ asked about the sterilization method of the dental instruments. The majority of respondents perceived that wearing gloves, masks, eyewear, and face shields would protect both the dentists and patients (Figure 1).

\section{Discussion}

Following the guidelines for infection control and applying the necessary prevention measures are crucial to prevent the transmission of blood, saliva, aerosol-borne infections, and other dental infections during dental treatments. To raise awareness of patient safety concerns and minimize risks for both patients and practices during dental treatments, teaching and remediation should be provided. ${ }^{13}$ It is also crucial to evaluate patients' attitudes to support infection transmission risk management strategies which are used by oral health personnel in making patient care safer. ${ }^{10}$ Another benefit of increasing the level of knowledge, awareness, and attitude of dentistry patients is to motivate healthcare workers to take maximum safety precautions, increase the quality of dental treatment and involve the patients in the infection control process.

In the current study, $93.6 \%$ of the participants achieved sufficient knowledge scores about cross-infection and infection control. On the other hand, previous studies had revealed lower knowledge scores. A study conducted by Ibrahim et al. showed that approximately two-fifths of the respondents had insufficient knowledge about infection control in dentistry. ${ }^{5}$ One of the reasons for the patients' high knowledge scores in the present study was the current COVID-19 pandemic.

During the pandemic process, CDC guidelines for crossinfection control changed and dentists were obliged to implement modified infection control protocols. Besides, patient awareness regarding COVID-19 transmission has also enhanced due to the influx of information through social media. ${ }^{1 / 4}$ Similarly, the findings obtained in the current study showed that social media was the main source of respondents' information about dental infections. Nowadays, social media is considered an accessible and effective way to gather information and increase awareness about health. ${ }^{15}$ Although social media is an accessible and effective way of provid- 
Table 1. Relationship between the levels of knowledge about dental infection and socio-demographic status of the participants in the present study

\begin{tabular}{|c|c|c|c|c|c|c|}
\hline \multirow[b]{2}{*}{ Variables } & \multirow[b]{2}{*}{ Mean/ SD } & \multicolumn{5}{|c|}{ Knowledge level n (\%) } \\
\hline & & $P$ & Poor & Fair & Satisfactory & $P$ \\
\hline \multicolumn{7}{|l|}{ Gender } \\
\hline Male & $10.5 \pm 1.6$ & \multirow{2}{*}{$0.005^{*}$} & $1(0.4 \%)$ & $11(4.4 \%)$ & $104(41.6 \%)$ & \multirow{2}{*}{0.053} \\
\hline Female & $11 \pm 1.3$ & & $0(0.0 \%)$ & $4(1.6 \%)$ & $130(52 \%)$ & \\
\hline \multicolumn{7}{|l|}{ Residence } \\
\hline Metropolitan city & $10.5 \pm 1.4$ & \multirow{4}{*}{$0.012 *$} & $0(0.0 \%)$ & $2(0.8 \%)$ & $39(15.6 \%)$ & \multirow{4}{*}{0.324} \\
\hline City & $11 \pm 1.3$ & & $0(0.0 \%)$ & $8(3.2 \%)$ & $135(54 \%)$ & \\
\hline Town & $10.4 \pm 1.8$ & & $1(0.4 \%)$ & $5(2 \%)$ & $43(17.2 \%)$ & \\
\hline Village & $10.9 \pm 0.9$ & & $0(0.0 \%)$ & $0(0.0 \%)$ & $17(6.8 \%)$ & \\
\hline \multicolumn{7}{|l|}{ Level of education } \\
\hline$\geq$ University & $11.1 \pm 1.3$ & \multirow{4}{*}{0.305} & $0(0.0 \%)$ & $1(0.4 \%)$ & $32(12.9 \%)$ & \multirow{4}{*}{0.342} \\
\hline University & $10.9 \pm 1.4$ & & $0(0.0 \%)$ & $7(2.8 \%)$ & $93(37.3 \%)$ & \\
\hline High school & $10.5 \pm 1.7$ & & $1(0.4 \%)$ & $7(2.8 \%)$ & $69(27.7 \%)$ & \\
\hline Elementary school & $10.9 \pm 1$ & & $0(0.0 \%)$ & $0(0.0 \%)$ & $39(15.7 \%)$ & \\
\hline \multicolumn{7}{|l|}{ Profession } \\
\hline Health-care worker & $11.5 \pm 1$ & \multirow{4}{*}{$0.003^{*}$} & $0(0.0 \%)$ & $0(0.0 \%)$ & $35(14 \%)$ & \multirow{3}{*}{0.225} \\
\hline Other professions & $10.6 \pm 1.6$ & & $1(0.4 \%)$ & $11(4.4 \%)$ & $111(44.4 \%)$ & \\
\hline Unemployed/student & $10.8 \pm 1.3$ & & $0(0.0 \%)$ & $4(1.6 \%)$ & $88(35.2 \%)$ & \\
\hline \multicolumn{6}{|l|}{ Income } & \\
\hline >Minimum wage X3 & $10.8 \pm 1.5$ & \multirow{4}{*}{0.538} & $0(0.0 \%)$ & $3(1.2 \%)$ & $36(14.4 \%)$ & \multirow{4}{*}{0.362} \\
\hline >Minimum wage X2 & $10.9 \pm 1.3$ & & $0(0.0 \%)$ & $4(1.6 \%)$ & $74(29.6 \%)$ & \\
\hline Minimum wage & $10.6 \pm 1.5$ & & $0(0.0 \%)$ & $7(2.8 \%)$ & $74(29.6 \%)$ & \\
\hline$<$ Minimum wage & $10.9 \pm 1.4$ & & $1(0.4 \%)$ & $1(0.4 \%)$ & $50(20 \%)$ & \\
\hline \multicolumn{7}{|l|}{ Source of knowledge } \\
\hline Social media & $10.7 \pm 1.3$ & \multirow{5}{*}{0.631} & $0(0.0 \%)$ & $2(0.8 \%)$ & $74(29.6 \%)$ & \multirow{5}{*}{0.348} \\
\hline Television & $10.4 \pm 1.7$ & & $0(0.0 \%)$ & $3(1.2 \%)$ & $21(8.4 \%)$ & \\
\hline Books/newspaper & $10.8 \pm 1.7$ & & $0(0.0 \%)$ & $3(1.2 \%)$ & $18(7.2 \%)$ & \\
\hline Family/friends & $10.8 \pm 1.4$ & & $0(0.0 \%)$ & $4(1.6 \%)$ & $49(19.6 \%)$ & \\
\hline Other sources & $10.9 \pm 1.4$ & & $1(0.4 \%)$ & $3(1.2 \%)$ & $72(28.8 \%)$ & \\
\hline
\end{tabular}

Table 2. Rates of the responses about self-reporting practices of participants towards the cross-infection measures in dental clinics

\begin{tabular}{|c|c|c|c|c|c|}
\hline \multirow[b]{2}{*}{ Questions } & \multicolumn{4}{|c|}{ Answers n (\%) } & \multirow[b]{2}{*}{$P$} \\
\hline & Yes & No, don't care & No, I am shy & No, never think of it. & \\
\hline $\begin{array}{l}\text { Do you question whether the dentist has a contagious } \\
\text { disease? }\end{array}$ & $73(29.2 \%)$ & $40(16 \%)$ & $58(23.2 \%)$ & $49(31.6 \%)$ & $0.002 *$ \\
\hline $\begin{array}{l}\text { Do you question the sterilization method of dental } \\
\text { instruments? }\end{array}$ & $90(36 \%)$ & $36(14.4 \%)$ & $47(18.8 \%)$ & $77(30.8 \%)$ & $0.000^{*}$ \\
\hline $\begin{array}{l}\text { If the dentist didn't wash his/her hands before and after } \\
\text { dental procedures, would you remind? }\end{array}$ & $136(54.4 \%)$ & $19(7.6 \%)$ & $47(18.8 \%)$ & $48(19.2 \%)$ & $0.000^{*}$ \\
\hline If the dentist didn't wear gloves, would you warn? & $192(76.8 \%)$ & $10(4 \%)$ & $31(12.4 \%)$ & $17(6.8 \%)$ & $0.000 *$ \\
\hline $\begin{array}{l}\text { If the dentist touched another surface (phone, computer } \\
\text { etc.) during treatment, would you remind to replace } \\
\text { gloves? }\end{array}$ & $158(63.2 \%)$ & $19(7.6 \%)$ & $41(16.4 \%)$ & $32(12.8 \%)$ & $0.000 *$ \\
\hline If the dentist didn't wear face mask would you warn? & $189(75.6 \%)$ & $13(5.2 \%)$ & $32(12.8 \%)$ & $16(6.4 \%)$ & $0.000 *$ \\
\hline $\begin{array}{l}\text { If the dentist didn't wear protective eyewear or face } \\
\text { shield, would you warn? }\end{array}$ & $135(54 \%)$ & $44(17.6 \%)$ & $37(14.8 \%)$ & $34(13.6 \%)$ & $0.000 *$ \\
\hline
\end{tabular}

ing information and the main source of participants in the present study, we should note that not all websites provide accurate information.

In the present study, $98.4 \%$ of respondents expect dentists to wear protective gloves during examination and treatment. This result was consistent with the studies conducted by Baseer et al. (98.7\%) and Azodo et al. (98.3) ${ }^{6,16}$ In contrast, Ibrahim et al. $(89.8 \%)$ and Barghout et al. (83.5\%) reported lower rates than the current study. ${ }^{5,17}$ Barghout et al. also stated that the prevention of infection spreads from one patient to another (65.8\%) and patient to the dentist $(53.5 \%)$ were the most frequently mentioned reasons for the necessity of using protective gloves. ${ }^{17}$ In a study conducted by Otuyemi et al. in $2001,64 \%$ of participants felt that gloves were worn to protect both the patient and the dentist. ${ }^{18}$ However, in the present study, the majority (96.8\%) of the respondents agreed that wearing gloves by the dentist during dental procedures protects both the dentist and patients. This inconsistency in rates may be because the studies being conducted at different time intervals and populations.

In the present study, most of the respondents had positive attitudes towards using masks (96\%), protective eyewear (85.2\%) and face shield (82.4) to prevent cross-infection during dental practice. Sofola et al. reported in their study that regardless of their educational background, many patients appear to be uneasy when the facemask is used. Patients with low socio-economic status stated that they feel embarrassed when the facemask is used since they tend to think that the facemask is used to prevent the inhalation of bad breath from the patient. ${ }^{12}$ However, in a recent study conducted in $2017,96.9 \%$ and $54.7 \%$ of the respondents perceived the necessity of wearing facemask and eyeglasses by dentists during dental procedures, respectively. ${ }^{5}$ Similarly, Barghout et al. reported that $74.8 \%$ and Deogade et al. stated that $93.5 \%$ of the respondents were believed that the dentist must wear facial masks. ${ }^{17,19}$ These studies highlighted the increasing awareness about the use of protective 
equipment in dental treatments.

Various studies have reported that the level of education is a crucial factor in the knowledge about the ways of transmission and infection control measures. ${ }^{5,11}$ In the current study, although the knowledge scores increased with the level of education, no statistically significant difference was observed. The general awareness of cross-infection and infection control methods revealed in this study can be attributed to the widespread use of modern information sources, such as the internet. ${ }^{20}$ However, the level of knowledge of health workers was higher, as expected.

In the present study, there was a statistically significant difference in the questionnaire scores about cross-infection and preventive measures between males and females. This finding was consistent with various studies in the literature, which reported that females were more concerned with the cross-infection risks and preventive practices than males. ${ }^{6,19,21}$ This finding may be explained with that females' tendency to gather more health knowledge than males and they are less likely to take actions that could endanger their health. ${ }^{22}$

Although the level of knowledge has increased compared to previous years, there are still lacks in patients' attitudes and practices towards infection control measures. In cases where the dentist does not fully comply with the protective measures, the rate of warning or reminding the dentist is relatively low. These results highlighted the patients' role in the cross-infection control process. To ensure their own safety, patients should be educated and trained about the potential risks of cross-infection and infection control practices. In this regard, dentists play a vital role in empowering patients and providing them with a safe dental treatment environment.

\section{Conclusion}

The findings obtained in this study suggest that the patients had a satisfactory level of knowledge about cross-infection and infection control methods. However, assessing and improving patients' knowledge and attitudes will enable dental professionals to follow cross-infection control protocols more carefully and encourage the patients to be a part of the cross-infection prevention process in dental clinics.

\section{Author Contributions}

All authors contributed to the study conception and design. Data collection was performed by M.B.D. and data analysis was performed by M.T.A. The first draft of the manuscript was written by M.T.A. and all authors commented on previous versions of the manuscript. All authors read and approved the final manuscript.

\section{Conflict of Interest}

This research did not receive any specific grant from funding agencies in the public, commercial, or not for profit sectors.

\section{Authors' ORCID(s)}

M.T.A. $\quad 0000-0002-1762-830 \mathrm{X}$

M.B.D. $\quad 0000-0003-3794-4366$

\section{References}

1. Alharbi G, Shono N, Alballaa L, Aloufi A. Knowledge, attitude and compliance of infection control guidelines among den- tal faculty members and students in KSU. BMC Oral Health. 2019;19(1):7. doi:10.1186/s12903-018-0706-0.

2. Yüzbasioglu E, Saraç D, Canbaz S, Saraç YS, Cengiz S. A survey of cross-infection control procedures: knowledge and attitudes of Turkish dentists. J Appl Oral Sci. 2009;17(6):565-9. doi:10.1590/s1678-77572009000600005.

3. Binalrimal S, AlDrees A, AlWehaibi M, AlAsmary M, AlShammery A, AlHaidri E, et al. Awareness and compliance of dental students and interns toward infection control at Riyadh Elm University. GMS Hyg Infect Control. 2019;14:Doc10. doi:10.3205/dgkhoo0326.

4. Huang N, Pérez P, Kato T, Mikami Y, Okuda K, Gilmore RC, et al. SARS-CoV-2 infection of the oral cavity and saliva. Nat Med. 2021;27(5):892-903. doi:10.1038/s41591-021-01296-8.

5. Ibrahim NK, Alwafi HA, Sangoof SO, Turkistani AK, Alattas BM. Cross-infection and infection control in dentistry: Knowledge, attitude and practice of patients attended dental clinics in King Abdulaziz University Hospital, Jeddah, Saudi Arabia. J Infect Public Health. 2017;10(4):438-445. doi:10.1016/j.jiph.2016.06.002.

6. Baseer MA, Rahman G, Yassin MA. Infection control practices in dental school: A patient perspective from Saudi Arabia. Dent Res J. 2013;10(1):25. doi:10.4103/1735-3327.111763.

7. Curtis MA, Zenobia C, Darveau RP. The relationship of the oral microbiotia to periodontal health and disease. Cell Host Microbe. 2011;10(4):302-306. doi:10.1016/j.chom.2011.09.008.

8. Tada A, Watanabe M, Senpuku H. Factors influencing compliance with infection control practice in Japanese dentists. Int J Occup Environ Med. 2014;5(1):24.

9. Kohn WG, Collins AS, Cleveland JL, Harte JA, Eklund KJ, Malvitz DM. Guidelines for infection control in dental health-care settings-2003. MMWR Recomm Rep. 2003.

10. Bârlean L, Dănilă I, Balcoş C, Săveanu I, Balan A. Preventive attitudes towards infection transmission in dental offices in North-East Romania. Rev Med Chir Soc Med Nat Iasi. 2012;116(4):1209-1212.

11. Ozkurt Z, Tomruk CO, Gursoy H, Dolekoglu S, Kazazoglu E. Diş hekimliği pratiğinde çapraz enfeksiyon kontrolü: Hasta tutum ve duyarlılığının incelenmesi. Cumhuriyet Dent J. 2011;14(2):106-112.

12. Sofola $\mathrm{O}$, Uti O, Onigbinde O. Public perception of crossinfection control in dentistry in Nigeria. Int Dent J. 2005;55(6):383-387. doi:10.1111/j.1875-595x.2005.tbooo51.x.

13. Black I, Bowie P. Patient safety in dentistry: development of a candidate'never event'list for primary care. Br Dent J. 2017;222(10):782-788. doi:10.1038/sj.bdj.2017.456.

14. Ahmed MA, Jouhar R, Adnan S, Ahmed N, Ghazal T, Adanir N. Evaluation of Patient's Knowledge, Attitude, and Practice of Cross-Infection Control in Dentistry during COVID-19 Pandemic. Eur J Dent. 2020;14(S 01):S1-S6. doi:10.1055/s-00401721295.

15. Saleh A, Yang YH, Ghani WMNWA, Abdullah N, Doss JG, Navonil $\mathrm{R}$, et al. Promoting oral cancer awareness and early detection using a mass media approach. Asian Pac J Cancer Prev. 2012;13(4):1217-1224. doi:10.7314/apjcp.2012.13.4.1217.

16. Azodo C, Umoh A, Ehizele A. Nigerian patients' perception of infection control measures in dentistry. Int J Biomed Sci. 2021;6(4). doi:10.4103/npmj.npmj_576_21.

17. Barghout N, Al Habashneh R, Ryalat ST, Asa'ad FA, Marashdeh $M$. Patients' perception of cross-infection prevention in dentistry in Jordan. Oral Health Prev Dent. 2012;10(1):9.

18. Otuyemi O, Oginni A, Ogunbodele E, Oginni F, Olusile A. Patients' attitudes to wearing of gloves by dentists in Nigeria. East Afr Med J. 2001;78(4):220-222. doi:10.4314/eamj.v78i4.9068.

19. Deogade SC, Mantri SS, Sumathi K, Dube G, Rathod JR, Naitam D. Perceptions of dental outpatients toward cross-infection control measures in Jabalpur city. J Indian Assoc. 2016;14(3):338. doi:10.4103/2319-5932.189836. 
20. Ratnayake D, Medawela S, Jayasinghe R, Jayathilake S, de Silva $D$, Sitheeque $M$. Awareness of risk of cross-infection and infection-control measures among patients attending University Dental Hospital, Peradeniya, Sri Lanka. Journal of investigative and clinical dentistry. 2018;9(1):e12268. doi:10.1111/jicd.12268.
21. Thomson WM, Stewart JF, Carter KD, Spencer AJ. Public perception of cross-infection control in dentistry. Aust Dent J. 1997;42(5):291-296. doi:10.1111/j.1834-7819.1997.tbo0132.x.

22. Umberson D. Gender, marital status and the social control of health behavior. Soc Sci Med. 1992;34(8):907-917. doi:10.1016/0277-9536(92)90259-s. 